\title{
The Advanced Photon Source: A Status Report*
}

ANL/ CP- -74462

DE92 009730

\author{
D.M. Mills \\ Advanced Photon Source \\ Argonne National Laboratory \\ 9700 South Cass Avenue \\ Argonne, IL 60439
}

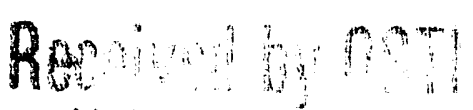

MAR 181992

*This work supported by the U.S. Department of Energy, BES-Materials Sciences, under contract no. W-31-109-ENG-38

\section{DISCLAIMER}

This report was prepared as an account of work sponsored by an agency of the United States Government. Nisther the United States Government nor any agency thereof, nor any of their Government. ither the United States Government nor any arsumes any legal liability or responsibility for the accuracy, completeness, or usefulness of any information, apparatus, product, or bility for the accuracy, completeness, or useiulness of any informe privately owned rights. Reference herein to any specific commercial product, rrowess, or service by trade name, trademark, manufacturer, or otherwise does not necessarily constitute or imply its endorsement, recommendation, or favoring by the United States Government or any agency thereof. The views and opinions of authors expressed herein do not necessarily state or reflect those of the United States Government or any agency thereof.

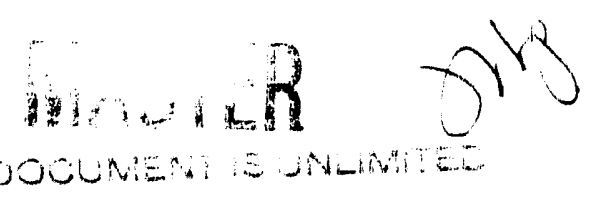




\title{
The Advanced Photon Source: A Status Report
}

\author{
Dennis M. Mills \\ Advanced Photon Sounce \\ Argonne National Laboratory \\ 9700 S. Cass Ave. \\ Argonne, IL 60439
}

The Advanced Photon Source (APS) currently under construction at Argonne National Laboratory is scheduled for completion in early 1996. Both conventional facilities construction and technical component fabrication is well underway. An update on the current state of civil construction as well as progress on storage ring and beamline technical component development will be presented.

User activities have also proceeded at a rapid pace, particularly over the last year. In response to a call for Proposals for sectors, the APS received proposals for over twenty sectors from prospective Collaborative Access Teams (CATs). It is anticipated that beamline construction in the experiment hall could begin in approximately 18 months. 


\section{Introduction}

When complete, the Advanced Photon Source (APS) being constructed at Argonne National Laboratory will generate hard $\mathrm{x}$-rays beams of unparalleled brilliance. The technical goals and design parameters for this national facility are given in Tables I and II, and a plan view of the APS is shown in Fig. 1. A more detailed description of the accelerator parameters and radiation properties of this third generation synchrotron radiation source have been published previously $[1,2]$. This manuscript describes on the current status of the facility.

\section{Conventional Facilities}

With the APS Project entering its seventh year of existence, approval to begin site preparations was granted by the U.S. Department of Energy in May of 1990. Some $\$ 36 \mathrm{M}$ in conventional facilities construction contracts have been awarded through FY 1991 as this activity began in earnest. Structural work on the linac/injection wing (which houses the linac, the positron accumulator ring [PAR], and the low-energy transport lines) is progressing rapidly (Figs. 2 and 3). Work is also well along on the utility building, which will process and distribute steam, deionized water, and hot and chilled water to the various buildings comprising the facility. Beneficial occupancy of these buildings is scheduled for the spring of 1992, at which time the linac components will be installed in order to begin pre-commissioning work. Advanced Photon Source conventional facilities will be completed and occupied in the following sequence: after the linac, the PAR, synchrotron, and storage ring/experiment hall buildings will be readied (See Fig. 1). The early assembly area (EAA), which lies in a beamline-devoid "shadow" area created by the placement of the rf equipment, will be the first completed segment of the experiment hall. The EAA will provide space where 
magnets and vacuum system components can be assembled and tested on their support girders prior to installation. The entire experiment hall structure is scheduled for occupancy in early 1994.

\section{Accelerator Systems Division}

Design and development of APS accelerator system technical components has been ongoing for several years. The lead time afforded by this rapid start and the expertise brought to the projest by APS staff are supporting the program goal of assembling a reliable, stable accelerator system within budget and on schedule.

The electron gun (Fig. 4) is the first major accelerator component to be procured. The gun test assembly, comprising the gun, Helmholtz coils, and accelerating structure, is being completed; a $60-\mathrm{MeV}$ accelerated test beam is expected soon.

The prototype storage ring copper radio frequency ( $\mathrm{rf}$ ) cavity, in spite of manufacturing delays, has been obtained on schedule for test, and low-level high order model (HOM) studies are complete. The first production synchrotron rf cavity (Fig. 5), manufactured by Interatom G.m.b.H., Germany, has been received for acceptance tests at the rf test stand constructed at Argonne. Progress toward delivery of all synchrotron rf cavities is currently 9 months ahead of schedule and procurement of these components is under the estimated cost.

The APS magnet design and production program is up and running at ANL. Based on measurements of the third and final storage ring quadrupole prototype, the design for this magnet has been finalized. A prototype storage ring sextupole (Fig. 6) has been assembled and is being measured. Two synchrotron dipole bending magnets have been successfully fabricated and assembled inhouse; measurement is in progress. Measurements on all proir types are now 
carried out at the APS Multipole and Dipole Measurement Facility at ANL. An APS magnet production facility has been brought on-line at ANL. Tooling for dipole, quadrupole, and sextupole cores has been designed, built, and installed. Stacking fixtures for the storage ring sextupole, storage ring quadrupole, and synchrotron dipole magnets have been optimized.

A second-generation prototype accelerator-system support girder will be available for tests in January of 1992. Improvements in this revised design are based on results of extensive vibration testing. A thermal/structural analysis has been performed to establish parameters of girder deformation in response to magnet cooling-water temperature and tunnel air temperature.

The accelerator vacuum system $R \& D$ program is nearing completion. An initial full-sector ( 5 segment) test of the vacuum system has been completed. A number of system modifications have resulted from the sector test. These include increasing the spacing between non-evaporable getter $(\mathrm{NeG})$ strips in regions where synchrotron radiation exists in order to avoid maximum missteered beam and redesign of the conflat through-hole. Automated conflat-welding studies have been completed. Installation of two automated conflat-welding systems at ANL is scheduled for early 1992, with pilot production of chambers to follow. NeGpumping tests, which are to be performed in collaboration with Lawrence Livermore Laboratory, will be evaluated during the Phase II full-sector test scheduled for December of 1991.

\section{Experimental Facilities Division}

Work is proceeding rapidly in many areas of the Experimental Facilities Division including design of front end (FE) components [3-8], insertion devices (IDs), and high heat load x-ray optical components. Major accomplishments 
have been made in developing and testing prototype position monitors [9], undulators [10-12], and high heat load monochromator crystals [13-15]. CVD diamond was employed for the first time as the blade material in a photoelectron position monitor [16]. The monitor was tested with the APS prototype undulator on the Cornell High Energy Synchrotron Source (CHESS). These CVD-diamond blades survived direct exposure to the beam. Work is now underway to further explore the long-term effects of synchrotron radiation on the mechanical and electrical properties of CVD diamond. Effort continues in the area of insertion device development. A $2.3 \mathrm{~m}$ long insertion device recently designed and built for use on the VUV ring at NSLS has met nearly all the magnetic tolerances required for insertion devices that will be installed on the APS. Several computer codes have also recently been updated for predicting the characteristics of insertion devices. In addition considerable progress is being made in the area of high heat load x-ray optics at the APS. Several experimental runs at existing facilities indicated that a new, inclined crystal geometry will handle power densities exceeding 100 watts $/ \mathrm{mm}^{2}$ with broadening of rocking curves of only fractions of an arc second. This bodes well for the meeting the APS design goal of 140 watts $/ \mathrm{mm}^{2}$ ( $7 \mathrm{GeV}, 100 \mathrm{ma}, 2.5$-m insertion device). Fig. 7 shows one of the prototype crystals before and after assembly.

In addition to these technical achievements, there is much activity on the user front. The Proposal Evaluation Board (PEB) recently reviewed the 19 Collaborative Access Team (CAT) Proposals that requested a total of 22 sectors. (Each sector consists of one bending magnet beamline and one insertion device beamline.) These 19 proposals represent a total of 432 principal investigators from universities, industry, research institutes, medical schools, and government laboratories. 


\section{Acknowledgements}

This work was supported by the U.S. Department of Energy, BES-Materials Science under contract no. W-31-109-ENG-38. The author would like to thank Rick Fenner, William Sproule, Drs. David Moncton, John Galayda, Jim Viccaro, Tunch Kuzay, and Gopal Shenoy for their technical input. The author also acknowledges Cheryl Zidel for her help in organizing and preparing this manuscript. 


\section{References}

1. "7-GeV Advanced Photon Source: Conceptual Design Report," Argonne National Laboratory Report ANL 87-15.

2. "Characteristics of the 7-GeV Advanced Photon Source: A Guide for Users," G. K. Shenoy, P. J. Viccaro, and D. M. Mills, Argonne National Laboratory Report ANL-88-9.

3. D. Shu, J. Barraza, T. Sanchez, R.W. Nielsen, J. T. Collins, and T.M. Kuzay, "Front End Designs for the 7-GeV Advanced Photon Source," presented at the 7th Nat. SRI Conf., LSU, Baton Rouge, LA, Oct. 1991.

4. T. M. Kuzay, J. T. Collins, A. M. Khounsary, and G. Morales, "Enhanced Heat Transfer With Metal-Wool-Filled Tubes," Proc. ASME/JSME Joint Conf., Book No. I0309E-1991, pp. 451-459.

5. T. H. L. Nian, A. I. C. Sheng, and T. M. Kuzay, "Thermal Stress Analysis of the Photon Shutter for APS Front Ends," presented at the 7th Nat. Conf. on SRI '91, LSU, Baton Rouge, LA, Oct. 1991. Submitted to Nuclear Instrumentation and Methods.

6. Z. Wang, D. Shu, and T. M. Kuzay, "Vibration Analysis of the Photon Shutter Designed for the Advanced Photon Source," presented at the 7th Nat. Conf. on SRI '91, LSU, Baton Rouge, Oct. 1991. Submitted to Nuclear Instrumentation and Methods.

7. R. J. Dejus, A. M. Khounsary, D. Brown, and P. J. Viccaro, "Calculations of Wiggler Spectrum and its Absorption in Media," presented at the 7th Nat. Conf. on SRI '91, LSU, Baton Rouge, LA, Oct. 1991. Submitted to Nuclear Instrumentation and Methods.

8. A. M. Khounsary, T. M. Kuzay, "On Diamond Windows for High Power Synchrotron X-ray Beams," presented at the 7th Nat. Conf. on SRI '91, LSU, Baton Rouge, LA, Oct. 1991.

9. D. Shu, B. Rodricks, J. Barraza, T. Sanchez, and T. M. Kuzay, "The APS Xray Undulator Photon Beam Position Monitor and Tests at CHESS and NSLS," presented at the 7th Nat. Conf. on SRI '91, LSU, Baton Rouge, Oct. 1991. Submitted to Nuclear Instrumentation and Methods.

10. B. Lai, P. J. Viccaro, R. Dejus, E. Gluskin, W.B. Yun, I. McNulty, C. Henderson, J. White, Q. Shen, and K. Finkelstein, "Tapering of the CHESSAPS Undulator: Results and Modelling," presented at the 7th Nat. Conf. on SRI '91, LSU, Baton Rouge, Oct. 1991. Submitted to Nuclear Instrumentation and Methods.

11. R. Dejus, A. M. Khounsary, D. A. Brown, and P.J. Viccaro, "Calculation of Wiggler Spectrum and its Absorption in Various Media," presented at the 
7th Nat. Conf. on SRI '91, LSU, Baton Rouge, Oct. 1991. Submitted to Nuclear Instrumentation and Methods.

12. R. Savoy, J. Maines, and P.J. Viccaro, "Periodic Magnetic Structure Design of APS Undulator A," presented at the 7th Nat. Conf. on SRI '91, LSU, Baton Rouge, Oct. 1991. Submitted to Nuclear Instrumentation and Methods.

13. A.M. Khounsary, "The Inclined Monochromator for High Power Synchrotron X-ray Beams," presented at the 7th Nat. Conf. on SRI '91, LSU, Baton Rouge, Oct. 1991. Submitted to Nuclear Instrumentation and Methods.

14. A. T. Macrander, W. K. Lee, R. K. Smither, and D. M. Mills, "High Heat Load Performance of an Inclined Crystal Monochromator with Liquid Gallium Cooling on the CHESS-ANL Undulator," presented at the 7th Nat. Conf. on SRI '91, LSU, Baton Rouge, Oct. 1991. Submitted to Nuclear Instrumentation and Methods.

15. R. K. Smither, W. K. Lee, A. T. Macrander, D. M. Mills, and S. Rogers, "Recent Experiments with Liquid Gallium Cooling of Crystal Diffraction Optics," presented at the 4th Intl. Conf. on SRI, SERC, Daresbury Laboratory, UK, Jul. 1991. Submitted to Rev. of Scientific Inst.

16. Patent applied for ANLAPS, Oct. 1991. 


\section{Figure Captions}

Figure 1. Plan view of the APS.

Figure 2. A view of the Advanced Photon Source construction site in October 1991. The foundation and structural steel beams for the injection complex (linac and positron accumulator ring) are clearly visible.

Figure 3. Aerial view of the linac/injection/synchrotron footprint.

Figure 4. The electron gun assembly, the first step in the APS acceleration process. Major linac injector components (gun assembly, prebuncher, first accelerating structure, Helmholtz focusing system, and spectrometer) have been procured and are being installed for beam diagnostics, phase and amplitude control, and optimization of the focusing magnetic profile. $60-\mathrm{MeV}$ test beam is expected by fall of 1991. (ANL photograph \#10812K)

Figure 5. APS synchrotron rf cavity manufactured by Interatom G.m.b.H., of Germany. (ANL photograph 10531K \#17A)

Figure 6. Prototype storage ring sextupole magnet. (ANL photograph 11683K, \#1)

Figure 7. An assembled (top) and as fabricated (bottom) silicon monochromator to be used in conjunction with the APS liquid gallium pump. Slots are cut into a silicon faceplate (bottom left) and then bonded to another piece of silicon (bottom right) into which manifold parts have been machined. The crystal assembly is ther mounted in a stainless steel holder assembly that attaches to the monochromator. The liquid gallium inlet/outlet lines can be seen attached to the crystal holder. 


$$
\because, \cdots+\cdots
$$

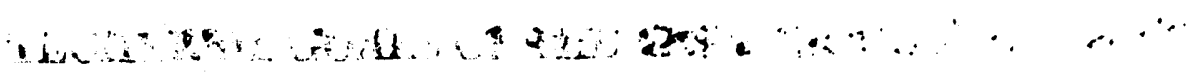

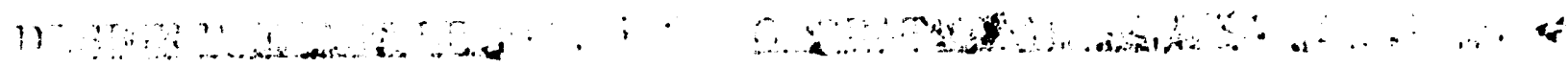
$\therefore \quad \therefore \quad \therefore \quad \therefore \quad, \quad \therefore$,

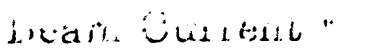

ivư shit

$\Gamma \cdot{ }^{\prime} \therefore{ }^{\prime} \therefore$

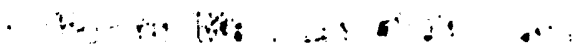

Bunch Duration

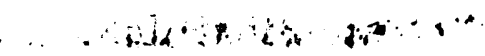

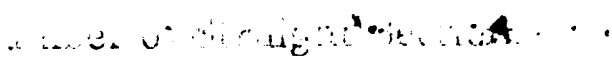

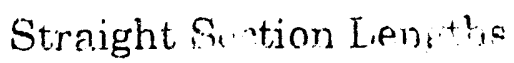

\section{0. $100 \mathrm{ps}$}

$$
\begin{aligned}
& \therefore \therefore \text { a con } 19 \\
& \text {. } \\
& \text { 5. n }
\end{aligned}
$$




\section{Table II}

\section{DESIGN PARAMETERS OF THE ACCELERATOR FACHITY}

- LINAC

- $200 \mathrm{MeV} \mathrm{e}^{-}(1.7 \mathrm{~A})$

- $450 \mathrm{MeV} \mathrm{e} \mathrm{e}^{+}(8 \mathrm{ma})$

- Repetition rate: $60 \mathrm{~Hz}$

- Length: $40 \mathrm{~m}$

- ACCUMULATOR

- $450 \mathrm{MeV}$ DC ring

- 24 linac pulses in $1 / 2$ second

- Damp position emittance

- Circumference: $30 \mathrm{~m}$

- BOOSTER

- $450 \mathrm{MeV}$ to $7 \mathrm{GeV}$ in $1 / 3$ second

- Repetition rate: $2 \mathrm{~Hz}$

- Circumference: $367 \mathrm{~m}$

- STORAGE RING

- 7.0 GeV 100-300 ma

- Lattice: Chasman-Green (40 periods)

- RF frequency: $352 \mathrm{MHz}$ (1296 buckets)

- Circumference: $1.104 \mathrm{~m}$

- Filling times under 1 minute (100 ma) 


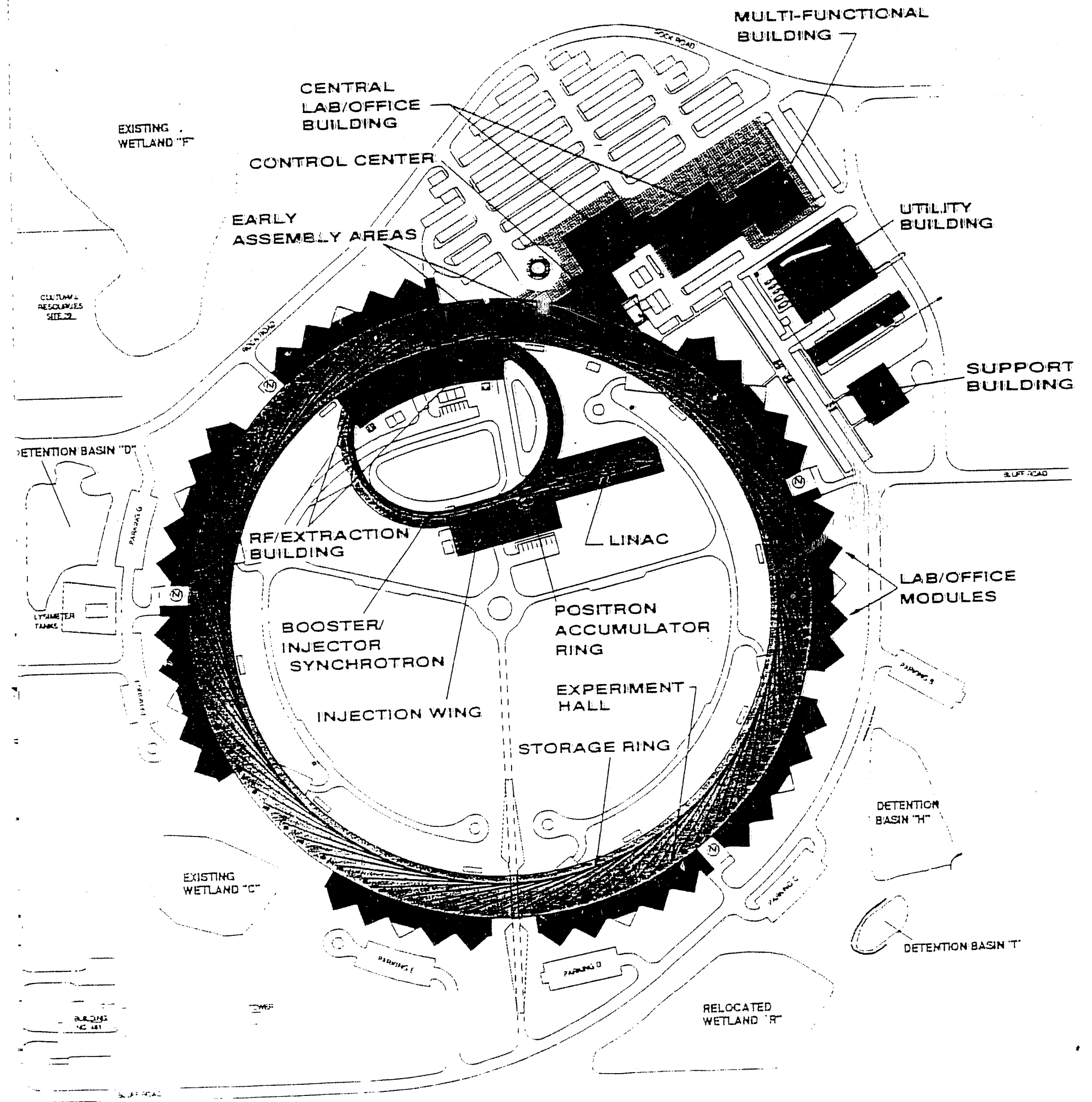

Figure 1 - Plan View of APS 


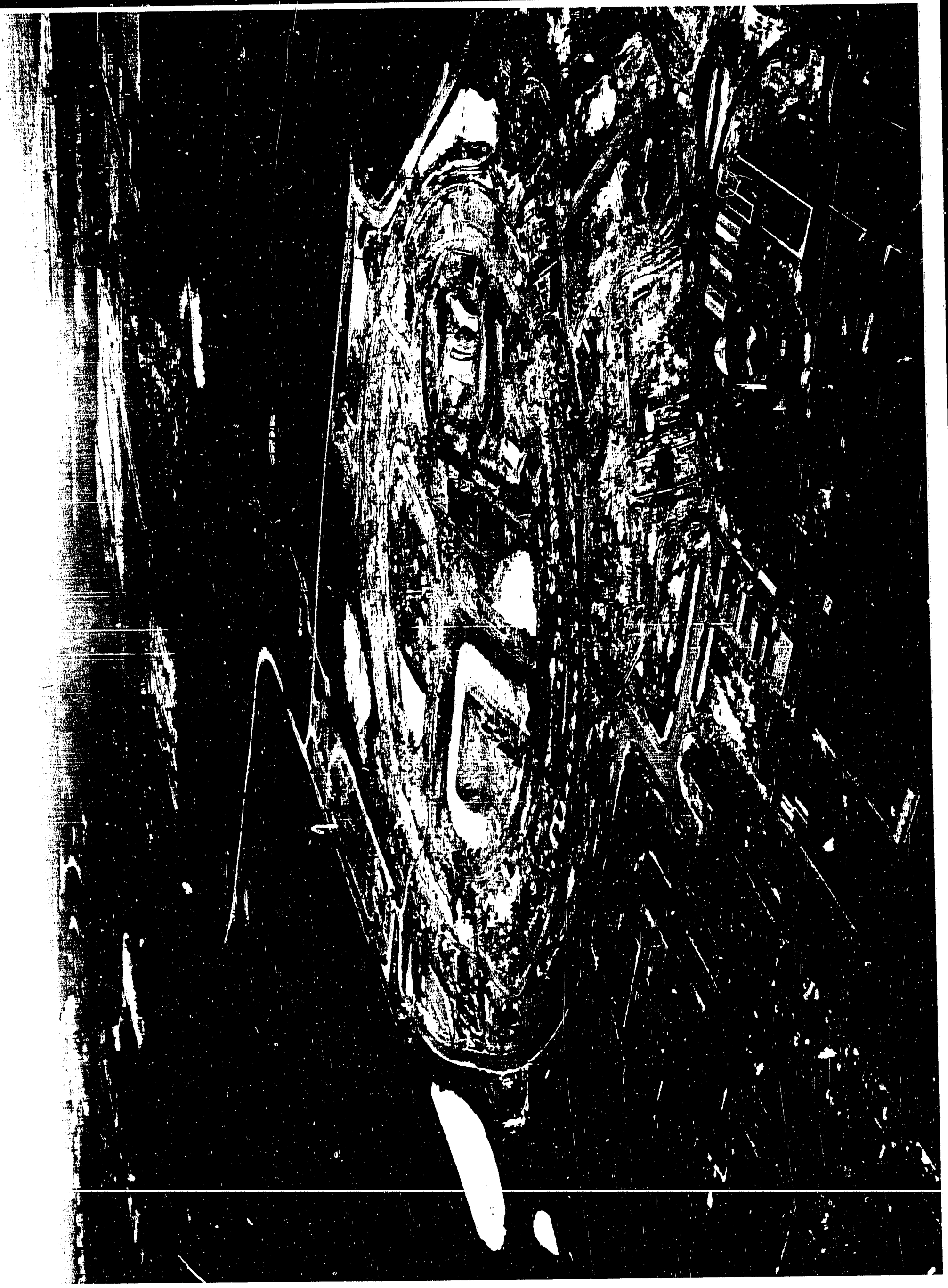




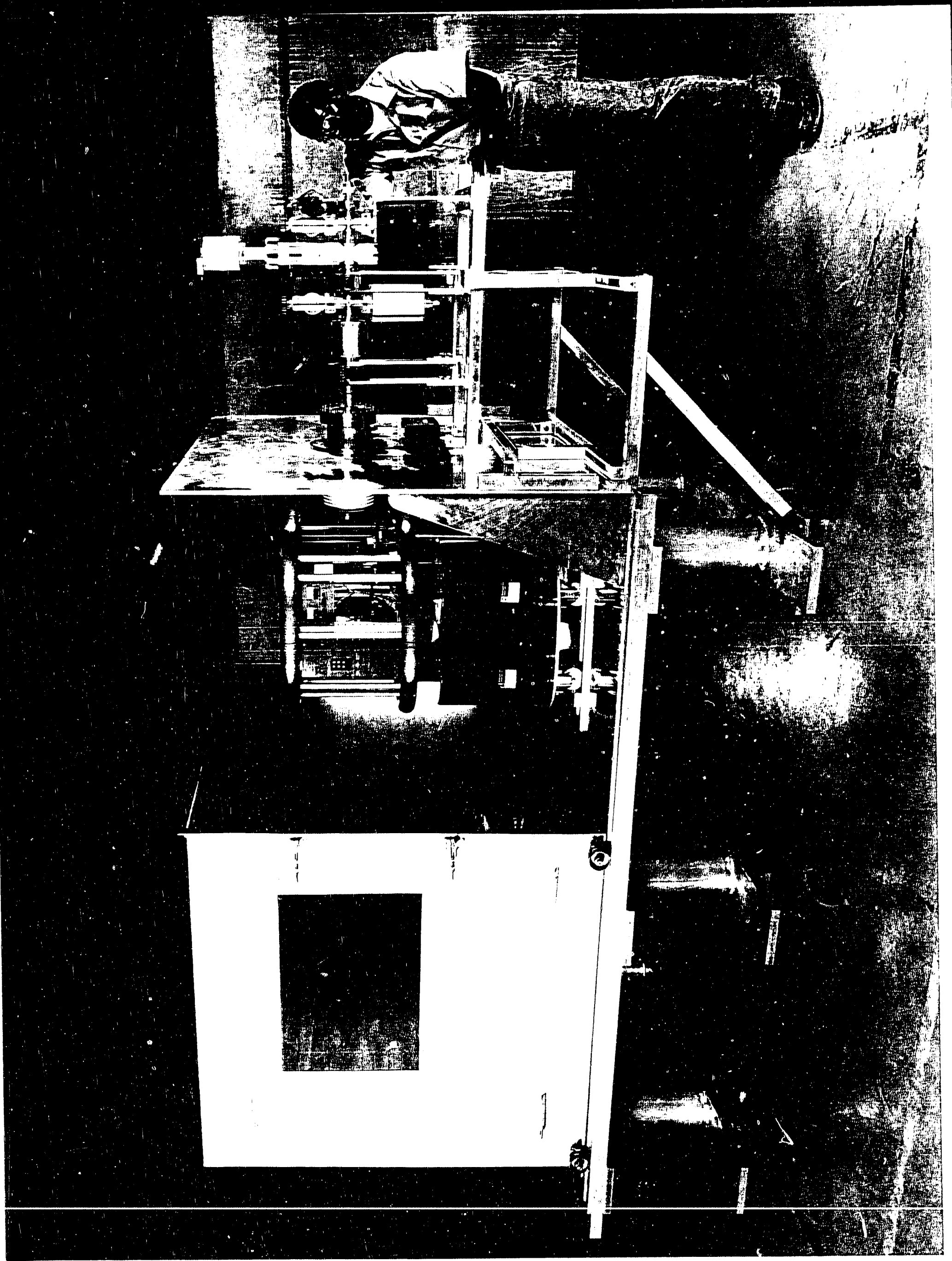




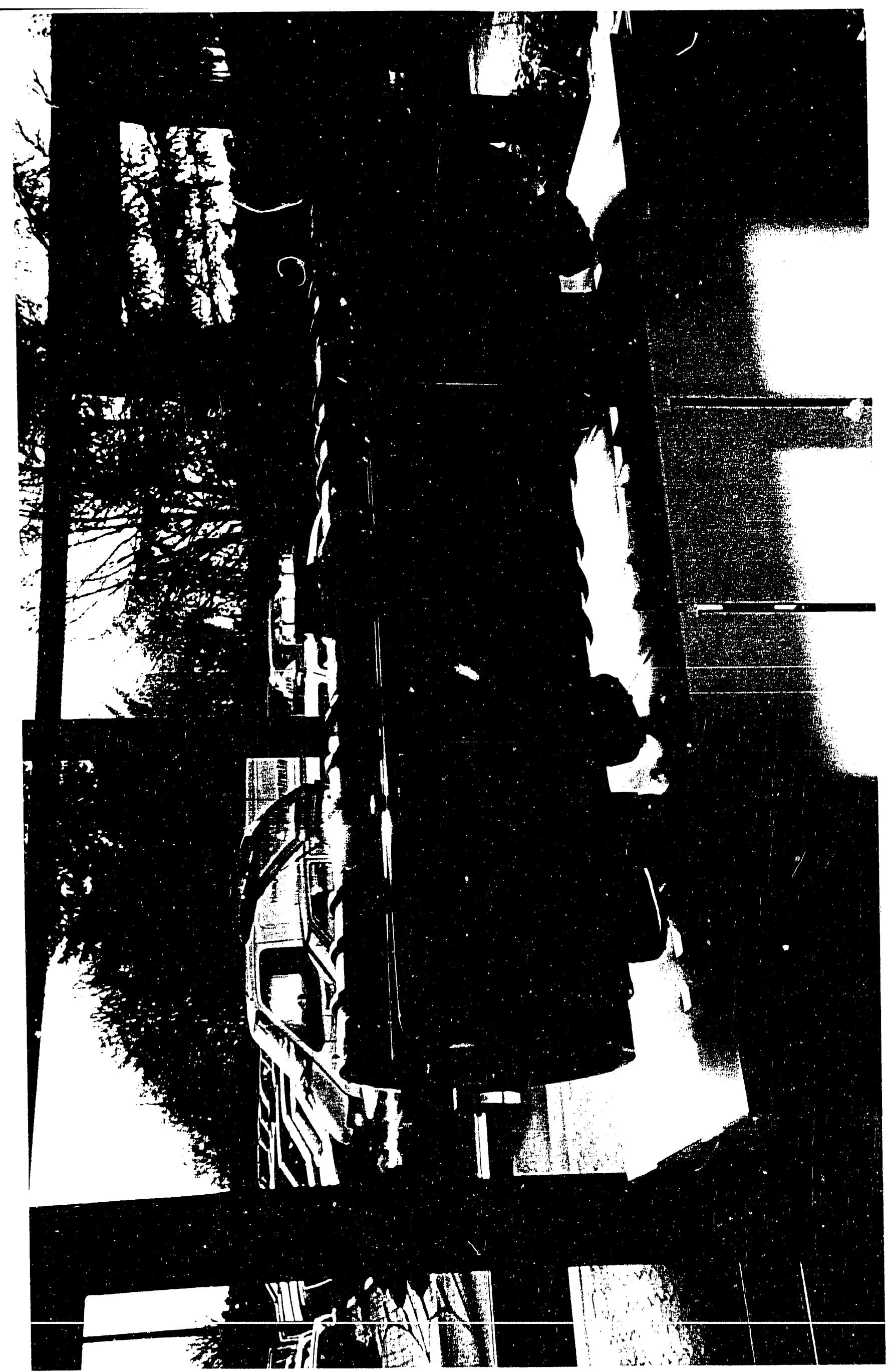




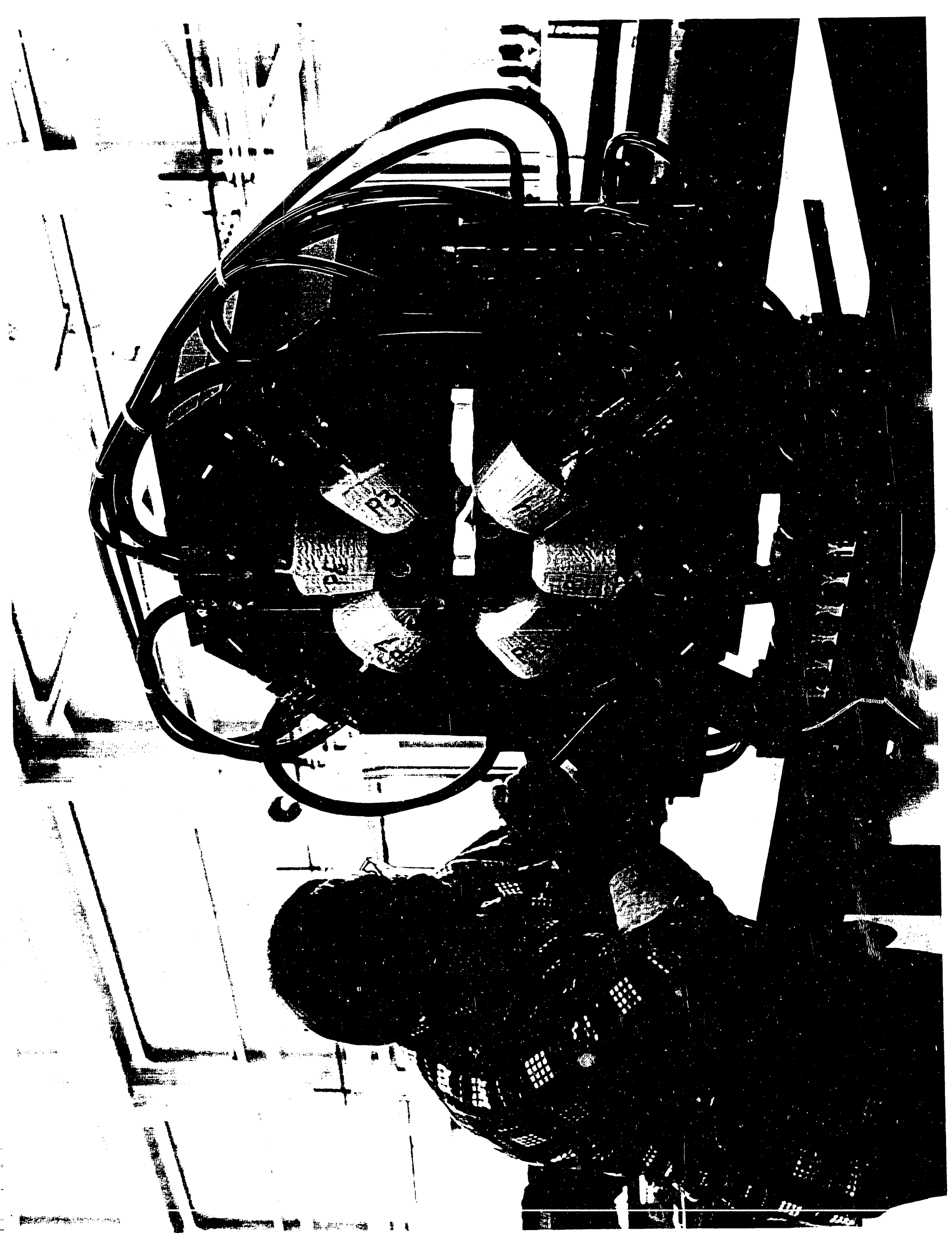



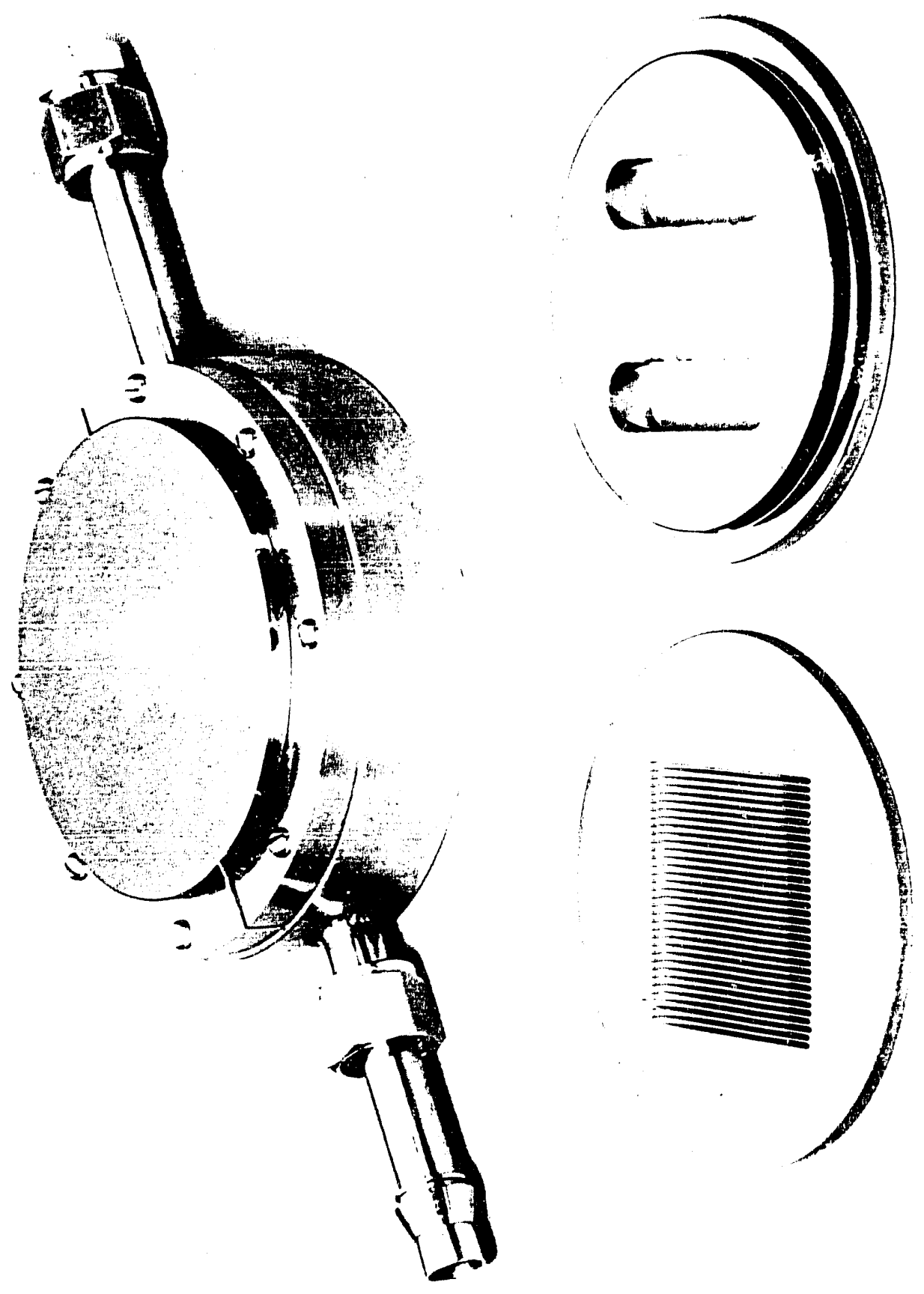

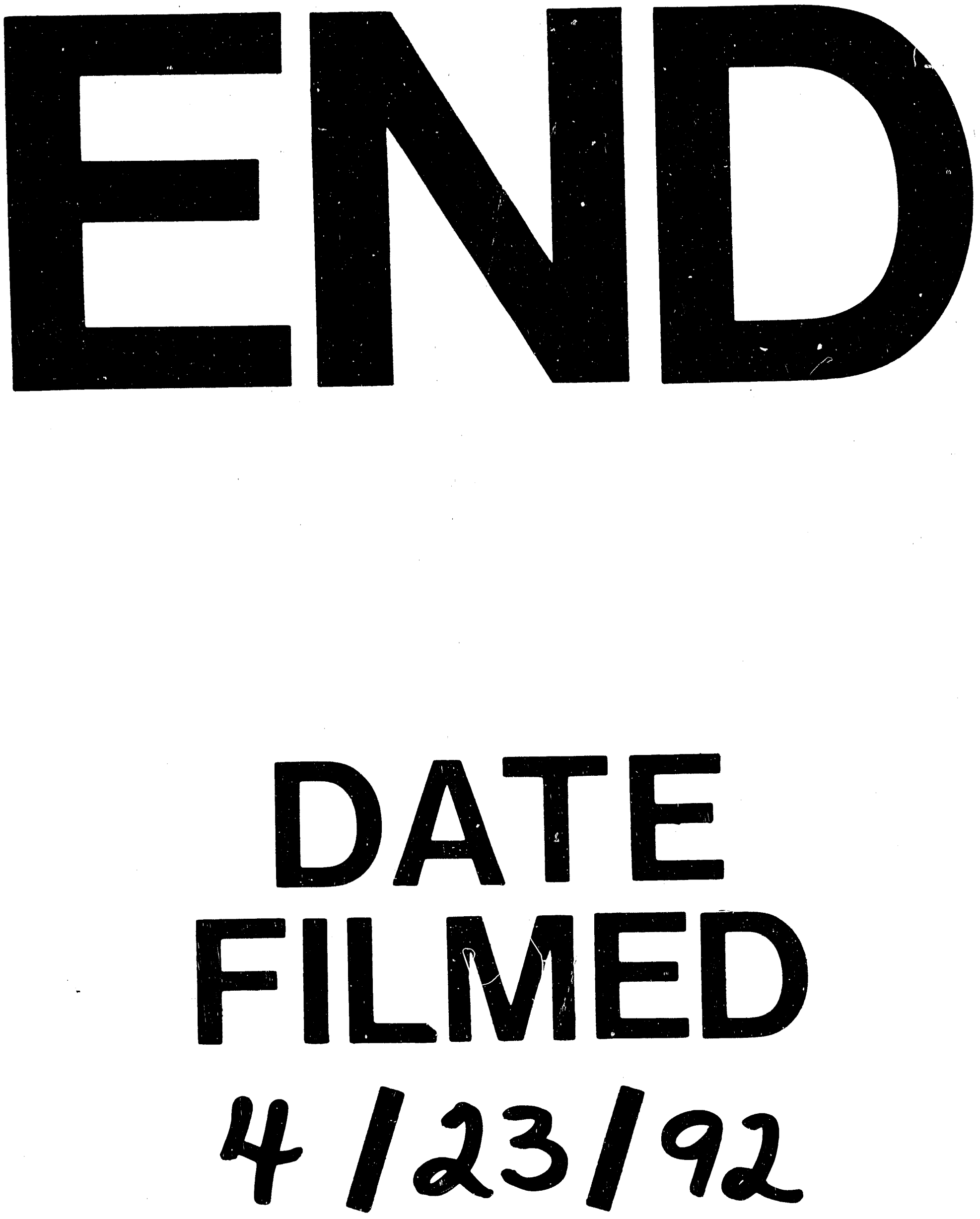

I 


$$
\text { }
$$

